\title{
Comparative quasi-static mechanical characterization of fresh and stored porcine trachea specimens
}

\author{
Benjamin J. Butler ${ }^{1,2}$, Alun Williams ${ }^{3}$, Alexander W. Tucker ${ }^{3}$, William G. Proud ${ }^{2,4}$, \\ and Katherine A. Brown ${ }^{1,2,5, \text { a }}$ \\ ${ }^{1}$ Surfaces, Microstructure and Fracture Group, Cavendish Laboratory, University of \\ Cambridge, JJ Thomson Avenue, Cambridge CB3 0HE, UK \\ 2 The Royal British Legion Centre for Blast Injury Studies, Department of \\ Bioengineering, Imperial College London, London SW7 2AZ, UK \\ ${ }^{3}$ Department of Veterinary Medicine, University of Cambridge, Madingley Road, \\ Cambridge CB3 0ES, UK \\ ${ }^{4}$ Institute of Shock Physics, Department of Physics, Imperial College London, \\ London SW7 2AZ, UK \\ ${ }^{5}$ Department of Chemistry, The University of Texas at Austin, Austin, TX 78712, \\ USA
}

Received 31 October 2017

Published online 10 September 2018

\begin{abstract}
Tissues of the upper airways of critically ill patients are particularly vulnerable to mechanical damage associated with the use of ventilators. Ventilation is known to disrupt the structural integrity of respiratory tissues and their function. This damage contributes to the vulnerability of these tissues to infection. We are currently developing tissue models of damage and infection to the upper airways. As part of our studies, we have compared how tissue storage conditions affect mechanical properties of excised respiratory tissues using a quasi-static platform. Data presented here show considerable differences in mechanical responses of stored specimens compared to freshly excised specimens. These data indicate that implementation of storage and maintenance procedures that minimize rapid degradation of tissue structure are essential for retaining the material properties in our tissue trauma models.
\end{abstract}

\section{Introduction}

The most common life-threatening hospital-acquired infection is pneumonia, primarily associated with mechanical ventilation and known as ventilator-associated pneumonia (VAP) [1]. The processes that result in these deep lung infections are thought to involve the transfer of bacteria from the oral cavity into upper respiratory tracheal and bronchial tissues, which may have been mechanically damaged from the insertion of a ventilator tube [2]. This damage may contribute to the occurrence

a e-mail: kb518@cam.ac.uk 
of localized infections in these tissues known as ventilator-associated tracheobronchitis (VAT) [3]. Understanding the relationship between damage and infection of upper respiratory tract tissues has considerable potential to inform and stimulate new therapies aimed at mitigating VAT and VAP.

The trachea is a multi-layered, fiber-oriented composite of soft tissues with viscoelastic material properties [4]. The structural stability of the trachea arises from its fibrous, collagen-rich hyaline cartilage. The non-linear and anisotropic material behaviors of the trachea are attributed to the extensive meshwork of fibers in its soft connective tissues [5]. The mechanical properties of trachea and its subcomponent tissues have been studied in a wide variety of mammalian species including specimens sourced from human cadavers. Samples have been studied under both compression and tension. For these specimens, the moduli ranges from the order of $10 \mathrm{kPA}$ to the order of $100 \mathrm{MPa}$ [6-10]. These variations in modulus values have been attributed to species-specific differences in the tissues and to sample orientation [6]. These variations have not been widely considered to be due to differences in sample preparation and storage.

As part of our aim to develop respiratory tissue-based models of damage and infection, we have undertaken comparative studies of trachea tissue specimens, stored under different conditions reported in the literature. In this paper, specimens of porcine tracheal tissues were excised and used immediately, stored in buffer, or frozen under conditions described in published studies that reported mechanical properties under compressive forces. Compression studies have been commonly used to assess the mechanical properties of fresh and stored tissues in a number of systems. For example, reports have recently been published on brain tissues [11], and intervertebral and temporomandibular joint discs $[12,13]$. In our studies, rapid preparation of samples enabled collection of compression data from very fresh tissues using an Instron platform. The main thrust of this work is to demonstrate the importance of sample storage as it relates to the interpretation of published mechanical properties of this tissue class, and as a driver for the development of realistic tissue models of mechanical injury to the trachea that can lead to complications such as VAT.

\section{Materials and methods}

\subsection{Tissue preparation}

Isogenic trachea tissues were obtained from a single six-week old piglet, sourced from a specific pathogen free (SPF) closed herd. The piglet was sacrificed by intravenous administration of sodium pentobarbitone at a dosage of $0.8 \mathrm{mg}$ per $\mathrm{kg}$ body mass. The bronchi were excised and opened with a scalpel to reveal the inner epithelial surface. Full thickness tissue samples from the trachea, containing all tissue components, were taken as circular discs using an 8-mm diameter biopsy punch.

Appropriately handled explants are extracted from host tissue and then kept at an air-liquid interface at room temperature. Samples sit on a 2\% agarose plug held in a plastic well containing phosphate buffered saline (PBS) solution, at the interface between the solution and water. All samples are tested within $12 \mathrm{~h}$ of extraction. As a point of comparison, two other storage protocols were examined. In the first, samples were completely submerged in PBS for $48 \mathrm{~h}$ and stored at $4{ }^{\circ} \mathrm{C}$ (fridge). In the second, dehydrated samples were stored at $-20^{\circ} \mathrm{C}$ for two weeks prior to testing (freezer).

Prior to testing, the discs were removed from PBS solution, if necessary, lightly dried, and relevant dimensions (diameter, thickness and weight) were measured (Tab. 1). The sample surfaces were often not precisely circular and, therefore, three 
Table 1. Details of porcine trachea biopsy punches.

\begin{tabular}{|c|c|c|c|c|c|c|}
\hline & \multicolumn{3}{|c|}{ Diameter $\pm 0.005 / \mathrm{mm}^{1}$} & \multirow{2}{*}{$\begin{array}{l}\text { Thickness } \\
\pm 0.005 / \mathrm{mm}\end{array}$} & \multirow{2}{*}{$\begin{array}{l}\text { Weight } \\
\pm 0.0005 / \mathrm{g}\end{array}$} & \multirow{2}{*}{$\begin{array}{l}\text { Density } \\
\pm 0.05 / \mathrm{g} / \mathrm{mL}\end{array}$} \\
\hline & 1 & 2 & 3 & & & \\
\hline Fresh 1 & 6.77 & 8.35 & 6.36 & 3.16 & 0.051 & 0.40 \\
\hline Fresh 2 & 7.59 & 8.07 & 7.36 & 4.73 & 0.058 & 0.26 \\
\hline Fresh 3 & 6.96 & 7.11 & 7.96 & 3.87 & 0.058 & 0.36 \\
\hline Fresh 4 & 6.89 & 8.96 & 10.25 & 3.10 & 0.098 & 0.53 \\
\hline Fridge 1 & 8.11 & 9.16 & 9.47 & 3.41 & 0.083 & 0.39 \\
\hline Fridge 2 & 11.95 & 8.15 & 10.60 & 4.08 & 0.119 & 0.36 \\
\hline Frozen 1 & 6.88 & 7.07 & 10.60 & 3.60 & 0.071 & 0.38 \\
\hline Frozen 2 & 7.68 & 7.04 & 8.70 & 3.28 & 0.062 & 0.40 \\
\hline Frozen 3 & 7.28 & 9.94 & 7.17 & 3.67 & 0.081 & 0.43 \\
\hline
\end{tabular}

${ }^{1}$ The column labels 1,2 and 3 are diameters of each sample, each made at $60^{\circ}$. Please see text for additional explanation.

measurements of the diameter (labelled 1, 2 and 3 ) were made at $60^{\circ}$ relative to one another and the resulting lengths averaged in the estimation of the samples' surface area for the purposes of calculating engineering stress. Although the samples were obtained using a circular biopsy punch, it is possible that pre-stress of the tracheal tissue may have contributed to the resulting elliptical shapes. The strain rate of all the experiments shown is $10^{0} \mathrm{~s}^{-1}$.

\subsection{Quasi-static measurements}

All data shown were collected with an Instron Model-6655 screw-driven press (Fig. 1). The samples were set between the lubricated faces of the anvil and the load cell. BlueHill software running on an integrated PC was used to input sample dimensions, testing parameters and to record the resulting data.

The faces of the anvil and load cell both had an approximate diameter of $\varnothing 30 \mathrm{~mm}$ and were sterilized with ethanol prior to the experiment. For the experiments shown, a $\pm 50 \mathrm{~N}$ load cell was used. This load cell has a published linearity and repeatability of $<0.25 \%$. With each load cell used, an initial test was conducted in the absence of any sample up to a safe load threshold to ascertain the load-dependent error in the measurement of sample height, due to the yield of the apparatus. This error correction factor was subtracted from all subsequent measurements.

Both Microsoft Excel and Matlab software was used to analyze the collected data. The data was plotted and viewed at a fixed magnification and the point at which the detected load deviated from $0 \mathrm{~N}$ was taken to be the full height of the sample. Engineering strain was back-calculated utilising this new figure for $0 \%$ strain.

\section{Results and discussion}

The averaged engineering stress-strain curves calculated for unconstrained trachea samples, collected as duplicates or triplicates from the same animal, is shown in Figure 2. The studies that we conducted into preferable storage and preparation protocols were based on published conditions used for studying the mechanical properties of trachea (e.g., $[6,9,10]$ ), namely, dry storage at $-20^{\circ} \mathrm{C}$ and buffered storage at $4{ }^{\circ} \mathrm{C}$. The results shown indicate both methods, but certainly the latter, have deleterious 


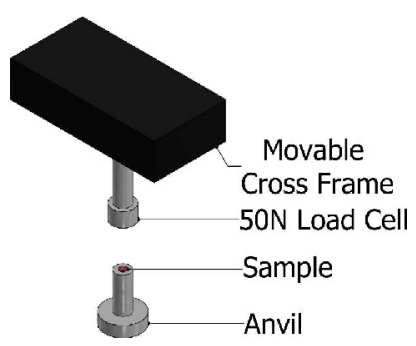

Fig. 1. Three-dimensional schematic image of the key components of the Instron screwdriven press. Biological samples were placed on the lightly-lubricated top surface of the stationary anvil. A load cell, certified to $50 \mathrm{~N}$ in the case of these experiments, attached to a movable cross frame is used to compress the sample at a pre-selected strain rate. The apparatus is controlled and data is extracted using BlueHill software running on a Windows PC.

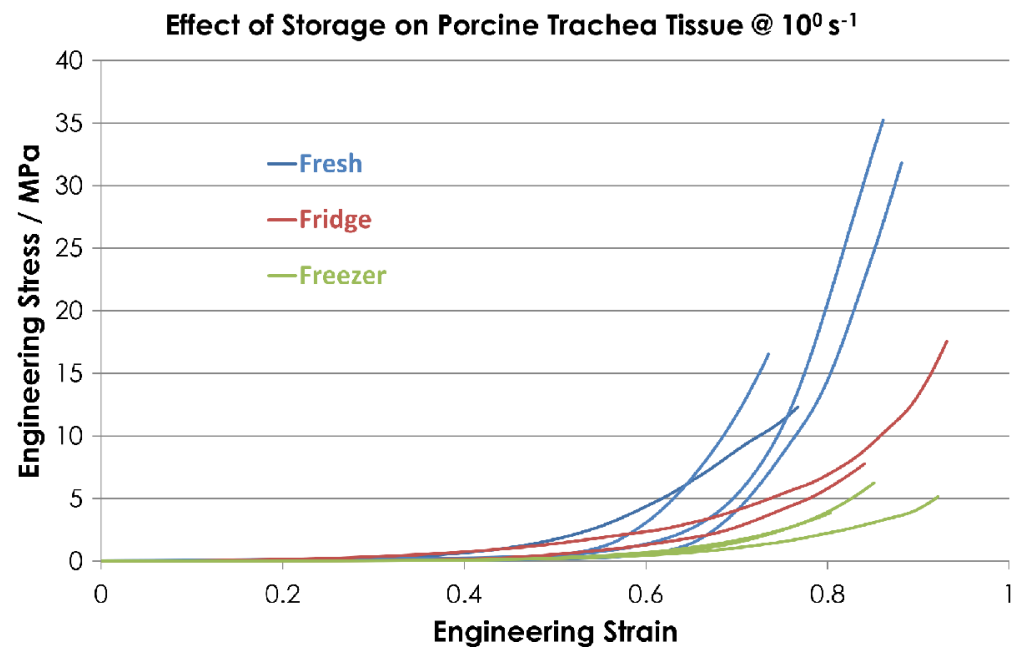

Fig. 2. Stress-strain data of porcine trachea samples. See text for details on sample size and measurements.

effects on the structure and, consequently, the material properties of biological samples. This conclusion appears to hold for samples obtained from different animals of the sample species. The less physiological the conditions in which the sample is kept, the greater the effect on it mechanical properties. Specifically, the act of freezing appears to greatly reduce the material stiffness of these biological samples.

Alterations in cell and tissue properties associated with freezing are generally associated with the physical processes involving water such as ice formation or dehydration that can affect cellular integrity and structures such as the extracellular matrix and its associated proteins [13-15]. Similar observations were made in a study by Ternifi et al. [16] that reported a large drop in the elastic modulus of kidney tissues that were subjected to freezing. These authors cited cellular crystallization, cell bursting and small vessel damage as possible causes. It is also probable that freezing has adverse affects on integrity of its collagen-rich structure that would in turn affect its biomechanical properties. In a related example, porcine growth explants of highly cartilaginous tissues associated with bone were stored in various conditions and studied under compression [17]. Interestingly, freezing of these explants resulted in a reduction of the collagen fibril modulus. This result suggested that the structural 
organization and/or composition associated with collagen in those samples had been disturbed.

The majority of the studies into the effects of long-term storage on tissue are restricted to the field of bioengineering. This is because it is of paramount importance that both decellularised scaffolds and recellularised, bioengineered replacements can be stored for prolonged periods of time prior to clinical use. For example, Baiguera et al. [18] studied the effects of long-term (1 year) storage on both the microstructure and mechanical properties of human decellularised tracheas. To investigate the impact of storing the samples at $4{ }^{\circ} \mathrm{C}$ in phosphate buffered saline on tissue structure required the use of histological techniques. A combination of ultrastructural and connective tissue staining highlighted the formation of pores and large interfibrillar spaces [7]. As could be hypothesised, this structural change had a detrimental effect upon the mechanical behaviours of stored tissues in comparison to fresh. The group conducted tensile experiments on samples utilising a universal testing machine. Tissues stored in this way exhibited a lower tensile modulus at both low and high strain (as determined by the knee of the curve on a stress-strain plot), lower tensile strength and a lower strain at the point of breakage. All of these parameters were reduced by approximately half as compared to fresh tissue.

Other studies have attempted to isolate the effect of hydration on tissue mechanical properties. Shahmirzadi and colleagues $[19,20]$ found that decreased hydration not only made the tissue stiffer but also slowed stress relaxation. Those results were obtained using aortic tissue submerged in liquids and required maintaining the samples at a hydration equilibrium. However, the utility of undertaking similar studies on tissues located air-liquid interfaces is questionable. For example, although respiratory mucosal tissues including trachea are coated in mucus and other surfactant molecules, full immersion and of these tissues into liquids does not represent a normal physiological environment and results in submersion stress that can alter tissue structure and function [21].

In summary, the studies presented here provide a clear indication that the mechanical properties of soft biological tissues alter significantly with short-term and long-term storage. Storing tissues in buffer at non-physiological temperatures degrades the integrity of the tissue and this effect is further exacerbated by storing the samples in even colder environments, over longer times, whilst dehydrated. These storage conditions (e.g., in buffer and frozen) are typical of conditions found throughout the literature of material studies of soft tissues. Our data suggest that past published studies may require re-interpretation, especially in cases where the information is used to understand tissue function under physiological conditions.

The Centre for Blast Injury Studies acknowledges the support of the Royal British Legion and Imperial College London. The Institute of Shock Physics acknowledges the support of the Atomic Weapons Establishment, Aldermaston, UK and Imperial College London. KAB acknowledges additional support from the Isaac Newton Trust, University of Cambridge and the European Office of Aerospace Research and Development. The on-going technical support of the machine shops at the Cavendish Laboratory and Imperial College London was crucial to this project.

\section{Author contribution statement}

$\mathrm{KAB}$ and $\mathrm{BJB}$ conceived the study. AWT and $\mathrm{AW}$ undertook animal studies related to isolation of the porcine tissues. BJB prepared tissues samples and carried out experimental characterization of material properties. Analysis of material properties was primarily carried 
by BJB with input from WGP. BJB and KAB interpreted the results and prepared the manuscript.

Open Access This is an open access article distributed under the terms of the Creative Commons Attribution License (http://creativecommons.org/licenses/by/4.0), which permits unrestricted use, distribution, and reproduction in any medium, provided the original work is properly cited.

\section{References}

1. A.Y. Peleg, D.C. Hooper, N. Engl. J. Med. 362, 1804 (2010)

2. M. Riou, S. Carbonnelle, L. Avrain, N. Mesaros, J.P. Pirnay, F. Bilocq, Int. J. Antimicrob. Agents 36, 513 (2010)

3. C.Y. Loo, W.H. Lee, P.M. Young, R. Cavaliere, C.B. Whitchurch, R. Rohanizadeh, Expert Rev. Anti Infect. Ther. 13, 379 (2015)

4. C.R. Roberts, J. K. Rains, P.D. Paré, D.C. Walker, B. Wiggs, J.L. Bert, J. Biomech. 31, 81 (1998)

5. Z. Teng, I. Ochoa, Z. Li, Z. Liao, Y. Lin, M. Doblare, Ann. Biomed. Eng. 37, 2380 (2009)

6. S.L. Codd, R.K. Lambert, M.R. Alley, R.J. Pack, J. Appl. Physiol. 76, 2627 (1994)

7. L. Wang, R. Tepper, J.L. Bert, K.L. Pinder, P.D. Paré, M. Okazawa, J. Appl. Physiol. 88, 1014 (2000)

8. L. Wang, P. Chitano, T.M. Murphy, Am. J. Physiol. Lung Cell. Mol. Physiol. 289, L902 (2005)

9. J. Wang, P. Mesquida, T. Lee, Conf. Proc. IEEE Eng. Med. Biol. Soc. 2011, 2089 (2011)

10. Z. Teng, J. Biomech. 45, 1717 (2012)

11. W. Zhang, L.F. Liu, Y.J. Xiong, Y.F. Liu, S.B. Yu, C.W. Wu, W. Guo, Sci. Rep. 8, $1247(2018)$

12. M. Azarnoosh, M. Stoffel, V. Quack, M. Betsch, B. Rath, M. Tingart, B. Markert, J. Mech. Behav. Biomed. Mater. 69, 169 (2017)

13. J.L. Calvo-Gallego, M.S. Commisso, J. Domínguez, E. Tanaka, J. Martínez-Reina, Mech. Behav. Biomed. Mater. 71, 314 (2017)

14. P. Mazur, Science 168, 939 (1970)

15. S. Park, A. Seawright, S. Park, J. Craig Dutton, F. Grinnell, B. Han, J. Mech. Behav. Biomed. Mater. 45, 32 (2015)

16. R. Ternifi, J.L. Gennisson, M. Tanter, P.J. Beillas, Mech. Behav. Biomed. Mater. 28, $68(2013)$

17. A.L. Ménard, C. Soulisse, P. Raymond, I. Londono, I. Villemure, J. Biomech. Eng. 136, 044502-1 (2014)

18. S. Baiguera, C. Del Gaudio, M.O. Jaus, L. Polizzi, A. Gonfiotti, C.E. Comin, P. Macchiarini, Biomaterials 33, 3662 (2012)

19. D. Shahmirzadi, A.H. Hsieh, Med. Eng. Phys. 32, 795 (2010)

20. D. Shahmirzadi, H.A. Bruck, A. Hsieh, Exp. Mech. 53, 405 (2013)

21. S.F. Nunes, P.R. Murcia, L.S. Tiley, I.H. Brown, A.W. Tucker, D.J. Maskell, J.L. Wood, Influenza Other Respir. Viruses 4, 7 (2010) 